\title{
BIOMEDICAL APPLICATIONS OF A COMMERCIAL CAPACITANCE TRANSDUCER
}

Edward Podolak

James B. Kinn

Edwin E. Westura, M.D.
Approved by

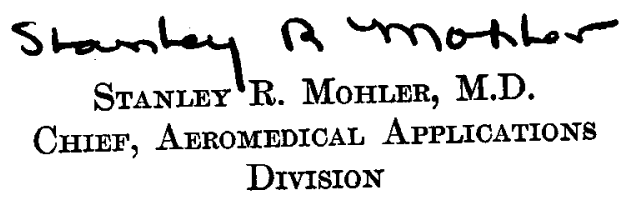

Released by

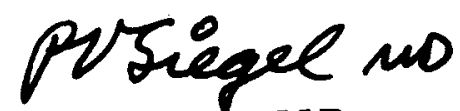

P. V. Stegel, M.D.

Federal AIr Surgeon

March 1968

DEPARTMENT OF TRANSPORTATION

FEDERAL AVIATION ADMINISTRATION

Office of Aviation Medicine 
Qualified requesters may obtain Aviation Medical Reports from Defense Documentation Center. The general public may purchase from Clearinghouse for Federal Scientific and Technical Information, U.S. Dept. of Commerce, Springfield, Va. 22151 


\section{BIOMEDICAL APPLICATIONS OF A COMMERCIAL CAPACITANCE TRANSDUCER}

\section{Introduction}

The detection and measurement of chest wall motions have been investigated in the past, using many different transducers $(1,2,3,4,6,7)$. These transducers can be divided into two groups-contacting and noncontacting. Experience is greatest using contacting transducers of various types (piezo-electric crystals, condenser microphones, carbon microphones, etc.). The problems inherent in these methods include the lack of DC response, lack of a linear response proportional to distance and distortion of the measurement due to contact.

In order to overcome these problems, noncontacting transducers have been developed using body capacitance (4) and photo-electric detection of light reflected from the vibrating surface (6). Again, linear response proportional to distance has been a problem with these devices. Berson and Pipberger reported a photo-electric method that detects the motion of a light-weight target riding on the chest (3).

Excellent reviews of the past methods in this area have been made by Groom (7), and Berson and Pipberger (3) have reviewed the instrumentation used and the problems of transducer design.

It is the purpose of this paper to report the use of a new commercially available noncontacting capacitive transducer* which produces a linear output proportional to distance and has a frequency response from $\mathrm{DC}$ to $10 \mathrm{KHz}$.

\section{Principle of Operation}

The design is centered on a high-gain feedback amplifier. An input reference signal consists of the current passed by a standard capacitor connected to a $50 \mathrm{KHz}$ oscillator. A feedback loop is completed by the capacitance formed between a probe and the structure under test, and feeds a current to the amplifier input

*B731A Vibration Meter, Southfield Electronic Sales, Inc. $2125010 \frac{1}{2}$ Mile Road Southfield, Michigan 48075. in opposition to the reference signal. The amplifier output voltage is therefore inversely proportional to the probe/structure capacitance and this, in turn, is inversely proportional to the probe/structure separation. Hence, the 50 $\mathrm{KHz}$ output from the amplifier has a mean amplitude determined by the mean distance between the probe and test structure, and is amplitude-modulated to an extent depending on the peak-to-peak vibration of the structure. A feedback voltmeter rectifies the $50 \mathrm{KHz}$ signal and indicates mean distance. A simplified schematic is shown in Figure 1. A more detailed circuit analysis is given in Appendix $\mathbf{A}$.

\section{Verification for Use in Physiological Measurements}

Although this device produces a linear output using flat metal surfaces, it had to be shown that its use can be extended to chest wall and pulse measurements. Under these conditions one side of the capacitor is skin which may have a curvature. Two sets of measurements were made to determine linearity when (1) skin is used as one side of the capacitor and when (2) curved surfaces are used.

To verify the use of this transducer on skin surfaces the probe surface was placed parallel to the skin on a finger which had been taped to a table top. The movement of the probe was monitored by means of a dial gauge. The probe separation as read on the distance meter and the dial gauge were both adjusted to read 0.100 inches and increments of about 0.010 inches were made as shown in Figure 2.

A second series of measurements were made to determine the effect of curved surfaces on the linearity. To do this the measurements were again referenced to the dial gauge and metal curved and flat surfaces were used as one plate of the capacitor. The results in Figure 3 show the response for the various surfaces with maximum deviation again at the small separation. 
These tests verify the use of this device for this application. The obvious lack of any loading feedback to the motion under study is assured because of the non-contacting feature. High magnetic fields had no measurable effect on the device's performance.

\section{Dynamic Characteristics}

The frequency response characteristics were determined at the U.S. Navy Ship Research and Development Center in Washington, D.C., using their shake tables. The results of this test are shown in Figure 4. The motion of the top of a calibrated accelerometer mounted on the shake tables was monitored and based on its calibration, the peak-to-peak displacement was calculated. In order to determine that the top of the accelerometer followed the motion of the table, a measurement to the table was made at $700 \mathrm{~Hz}$ as shown in the figure. The fall off of the response at the high end is due to a $1,000 \mathrm{~Hz}$ low-pass filter used in the output circuit of the vibration meter, and the low-end calibration was limited by the frequency characteristics of the shake table itself.

\section{Results}

The major applications of this device investigated thus far have been measurements of chest wall motion at the apex, point of maximum precordial impulse (apexcardiogram). A typical apexcardiogram (ACG) taken with a piezoelectric transducer is shown in Fig. 5, where the ACG, carotid pulse and phono were taken with conventional transducers. A displacement apexcardiogram of the same subject taken with the capacitance device is shown in Fig. 7 along with its first and second derivatives. Brachial arterial pulses (capacitance transducer) are shown in Fig. 6. No difficulty was experienced in measuring vessel pulses in both the brachial and radial arteries. Good results are dependent largely on patient cooperation and experience in placement of the probe.

Because of wide dynamic range and frequency response, it is possible to place the probe at the apex and with the subject breathing obtain a respiration tracing with a small variation superimposed on it (the apexcardiogram). Then by having the subject hold his breath and then increasing the gain of our recorder we could magnify this apexcardiogram and eliminate the curve of respiration. Also, with and without breathing depending on the range of the probe, low frequencies could be filtered out and heart sounds obtained.

The extended range and frequency response allowed electronic differentiation of the apex and brachial displacements for velocity and acceleration of the motion. An example of this is presented in Figure 7 and a comparison between acceleration made in this way and directly, using a sensitive miniature accelerometer* coupled to a special calibrated amplifier $\nmid$ is shown in Figure 8.

\section{Discussion}

Because this distance measurement requires the use of a disk capacitor plate rather than a point, the measurement inherently has some "averaging" of information. That the apex motion does not move so as to maintain a parallel relationship with this capacitor disk is also reason to expect some distance averaging. Exactly what this effect does to the frequency response and accuracy of the measurement must be investigated further or determined.

\section{Hazards Involved}

Subjects have occasionally reported burning sensations at the leg electrode (used for ground return) when other instruments such as on ECG were attached. The use of telemetry circumvented this problem.

When the instrument is used alone and with the probe making firm contact on the dry chest wall a burning sensation has been reported at the probe end. A thin plastic or rubber film has been wrapped around the probe and use successfully, i.e., with the probe making firm contact with the chest wall, no subject has ever reported any sensation or shock. However, the transducer must be recalibrated because of the additional dielectric material added.

Peak-to-peak voltage (guard ring to ground) and current measurement* (10 ohms in series with the guard ring circuit at the probe end) have been made for two conditions of the probe and three conditions of the test procedure for determining the hazard involved. The probe was used "uncovered" and "covered" with a thin

\footnotetext{
*Wilcoxon Accelerometer, Model 137.

†Ithaco Amplifier, Model 252.

*Tektronix 555 Scope, Type D Input, $1 \mathrm{Meg}$. Shunted $47 \mu \mu \mathrm{f}$.
} 
rubber film. Using a subject and with the probe open-circuited (not on scale) 60 volts and 350 ma. was read, rubber covered; and 52 volts and 350 ma. with the probe uncovered. Under normal test conditions with the probe not touching $(0.4$ meter reading) 5.2 volts and $36 \mathrm{ma}$. was read, rubber, covered; and 5.2 volts and 36 ma., uncovered. With the probe making firm contact with the chest wall 6.4 volts and 40 ma. was read, rubber covered; and 1 volt and $66 \mathrm{ma}$. uncovered and not motorboating. Under this condition of touching the subject with the probe rubber covered and uncovered, the carrier frequency shifts from the $50 \mathrm{KHz}$ normal operating frequency to $178 \mathrm{KHz}$. In addition, with the probe uncovered, and touching the subject, an unstable condition occurs in which the instrument starts motorboating at $6.6 \mathrm{~Hz}, 6$ volts and $90 \mathrm{ma}$. is read and a shock is reported.

It must be pointed out that this instrument was designed for industrial applications. Its use in this study was primarily for research purposes and in the hands of inexperienced or untutored personnel, this device may be hazardous, particu- larly if the subject or patient is also connected to other medical instrumentation.

\section{Summary}

We have described a capacitive displacement transducer with a linear response and constant sensitivity for a frequency range of $0-1,000 \mathrm{~Hz}$. Its application to measurement of chest wall motions was verified using static displacements from flat and curved surfaces and both metal and human tissue.

The transducer has been used to obtain recordings of apex motion, heart sounds, brachial and radial pulses.

Its advantages are that it is noncontacting and linear; that it has a wide frequency response and can easily be calibrated to obtain quantitation of actual motion.

Problems encountered in use were the mechanical positioning of the probe including respiratory motions in the measurement and the need to insulate the probe with a film of thin plastic to insure against any electrical hazards to the subject. 


\section{Appendix A}

See Fig. 1.

AND :

WHERE :

$V_{1}=$ Source potential.

$\mathrm{V}_{\mathrm{o}}=$ Amplifier output.

$\mathrm{R}=$ Grid resistor of amplifier input stage.

$\mathrm{C}_{\mathrm{s}}=$ Standard capacitance (of reactance $\mathrm{X}_{\mathrm{s}}$ ).

$\mathrm{C}_{\mathrm{u}}=$ Probe/structure capacitance (unknown, of reactance $X_{u}$ ).

$\mathrm{i}_{1}=$ Current passed by Standard.

$\mathrm{i}_{2}=$ Current fed back by probe capacitance structure.

e $=$ Potential across $R$.

$A=$ Amplifier gain.

THEN :

$\mathrm{V}_{\mathrm{o}}=\mathrm{A} \cdot \mathrm{e}$ and $\mathrm{e}=\left(\mathrm{i}_{1}-\mathrm{i}_{2}\right) \cdot \mathrm{R}$.

$\mathrm{A}>>1$ and $\mathrm{C}_{\mathrm{u}}$ is comparable with $\mathrm{C}_{\mathrm{s}}$.

THEREFORE :

$e \rightarrow 0$ and hence, for finite $R,\left(i_{1}-i_{2}\right) \rightarrow 0$, that is, $i_{1}=i_{2}$.

NOW:

$\mathrm{V}_{\mathrm{o}}=\mathrm{i}_{2} \cdot \mathrm{X}_{\mathrm{U}}($ if $\mathrm{e}=0)$.

$$
\begin{aligned}
& \mathrm{V}_{\mathrm{l}}=\mathrm{i}_{1} \cdot \mathrm{X}_{\mathrm{s}}(\text { if } \mathrm{e}=0) . \\
& \frac{\mathrm{V}_{\mathrm{o}}}{\mathrm{V}_{1}}=\frac{\mathrm{i}_{2}}{\mathrm{i}_{1}} \cdot \frac{\mathrm{X}_{\mathrm{u}}}{\mathrm{X}_{\mathrm{s}}} \\
& \mathrm{BUT}: \\
& \mathrm{i}_{1}=\mathrm{i}_{2} \cdot \cdot \mathrm{V}_{\mathrm{o}}=\mathrm{V}_{1} \cdot \frac{\mathrm{X}_{\mathrm{u}}}{\mathrm{X}_{\mathrm{s}}}
\end{aligned}
$$

BUT :

$V_{1}$ and $\mathrm{X}_{\mathrm{s}}$ are constant.

PUTTING :

$\mathrm{K}$ for $\mathrm{V}_{\mathrm{l}} / \mathrm{X}_{\mathrm{s}}, \mathrm{V}_{\mathrm{o}}=\mathrm{K} \cdot \mathrm{X}_{\mathrm{U}}$.

NOW :

$\mathbf{X}_{\mathrm{u}}=\frac{1}{w \mathrm{C}_{\mathrm{u}}}$ and $\mathrm{C}_{\mathrm{u}} \propto 1 / \mathrm{d}$, where $\mathrm{d}$ is the plate separation.

$\mathrm{V}_{\mathrm{o}}=\mathrm{K}^{\prime} \mathrm{d}$ where $\mathrm{K}^{\prime}$ is a new constant of proportionality.

The amplifier output $\left(V_{0}\right)$ is thus directly proportional to the probe/structure separation (d) and is independent of the amplifier gain. 


\section{Appendix B}

\section{Range of Probes:}

Six probes are available for use with the instrument. The standard probes have a flat, circular inner electrode surrounded by a guard ring. The electrode and guard ring are separated by an insulating sleeve. The probes are screwed into a probe holder mounted on the end of a coaxial cable.

The range of the probes for the instrument is:

\begin{tabular}{c|c|c|c}
\hline Probe & Effective probe radius & \multicolumn{2}{|c}{$\begin{array}{c}\text { Normal FSD } \\
\text { (Distance and Vibration) }\end{array}$} \\
\cline { 2 - 4 } & Inches & Inches & Millimeters \\
\cline { 2 - 3 } A & 0.0223 & 0.001 & 0.025 \\
B & 0.050 & 0.005 & 0.125 \\
C & 0.0707 & 0.010 & 0.25 \\
D & 0.158 & 0.050 & 1.25 \\
E & 0.223 & 0.100 & 2.50 \\
F & 0.500 & 0.500 & 12.5 \\
\hline
\end{tabular}

It should be noted that full scale deflection (FSD) of the meter corrésponds to 1 volt at the output of the filter. Therefore, the sensitivity for the $F$ Probe is 1 volt per 0.500 inches or 2 volts per inch deflection over the range of the probe, i.e., 0 to 0.500 inches. The sensitivity for the D Probe, one particularly useful for chest wall motions (apexcardiograms), is 1 volt per
0.050 inches or 20 volts per inch over the range 0 to 0.050 inches.

\section{BIBLIOGRAPHY}

1. Cembala, Damian. Bulletin De l'Acad. Pol. d Sc. et al., Litt., Cl.d. Mid. 1949.

2. Chlebus, H. Early stage of arteriosclerosis in cardiograms, 1959, Warsaw State Enterprise of Medical Publications, U.S. Joint Publications Research Service R-1995-D/B Dec. 5, 1961, p. 1-81.

3. Berson and Pipberger. Measurements of chest wall vibrations due to the activity of the heart. Journal of Applied Physiology 21(2) March 1966.

4. Dale Groom, Leonardo H. Medina, Y. T. Sinvonen. The proximity transducer, The American Journal of Medical Electronics, October-December 1964, p. 261265.

5. A. Benchimol and E. G. Diamond. The normal and abnormal apexcardiogram. Its physiologic variation and its relation to intracardiac events. American Journal of Cardiology September 1963, p. 368-382.

6. J. N. BERRY, A new method for recording cardiac, hepatic and other pulsations, movements and thrills. American Heart Journal, January 1966, p. 16-25.

7. The recording of heart sounds and vibrations, $I$. Historical Review and description of a new electronic direct-contact vibration pickup. Exp. Med. Surg. 14, 239-254, 1955.

8. Lyle Peterson. Methods in medical research VII, Robert Rushmer, editor, Year Book Medical Publishers, p. 3-4, 1966. 


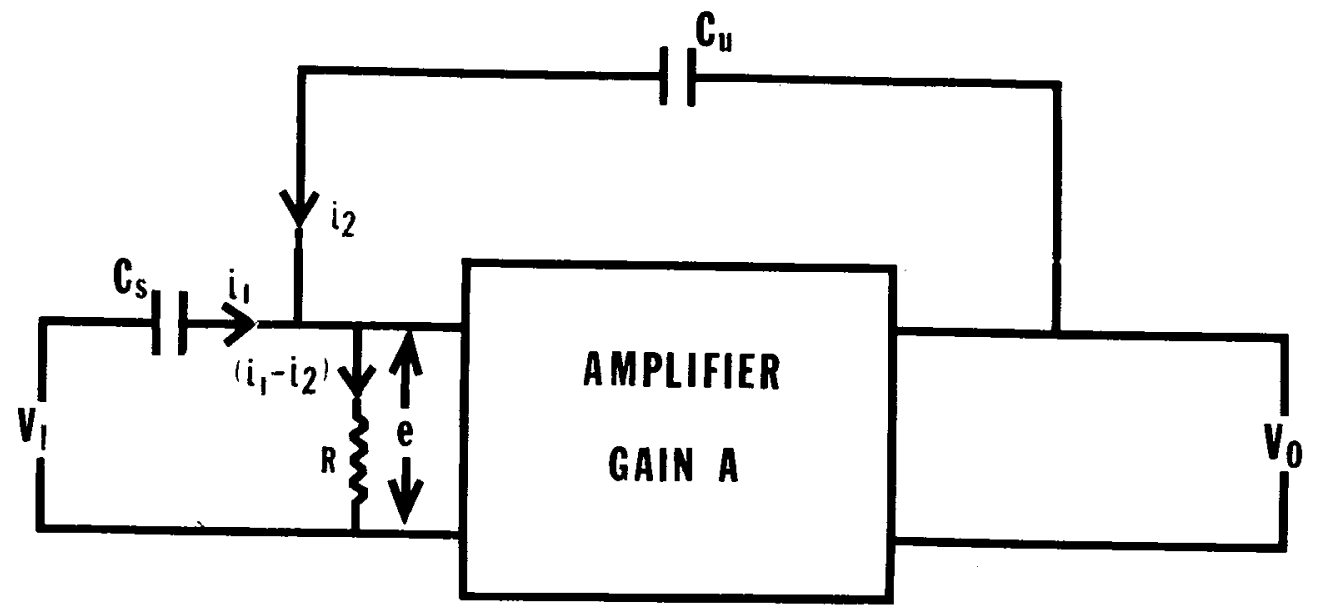

STANDARD $C_{S}$ HAS REACTANCE $X_{s}$ UNKNOWN $C_{u}$ HAS REACTANCE $X_{u}$

SCHEMATIC DIAGRAM

FIGURE 1. Simplified schematic diagram.

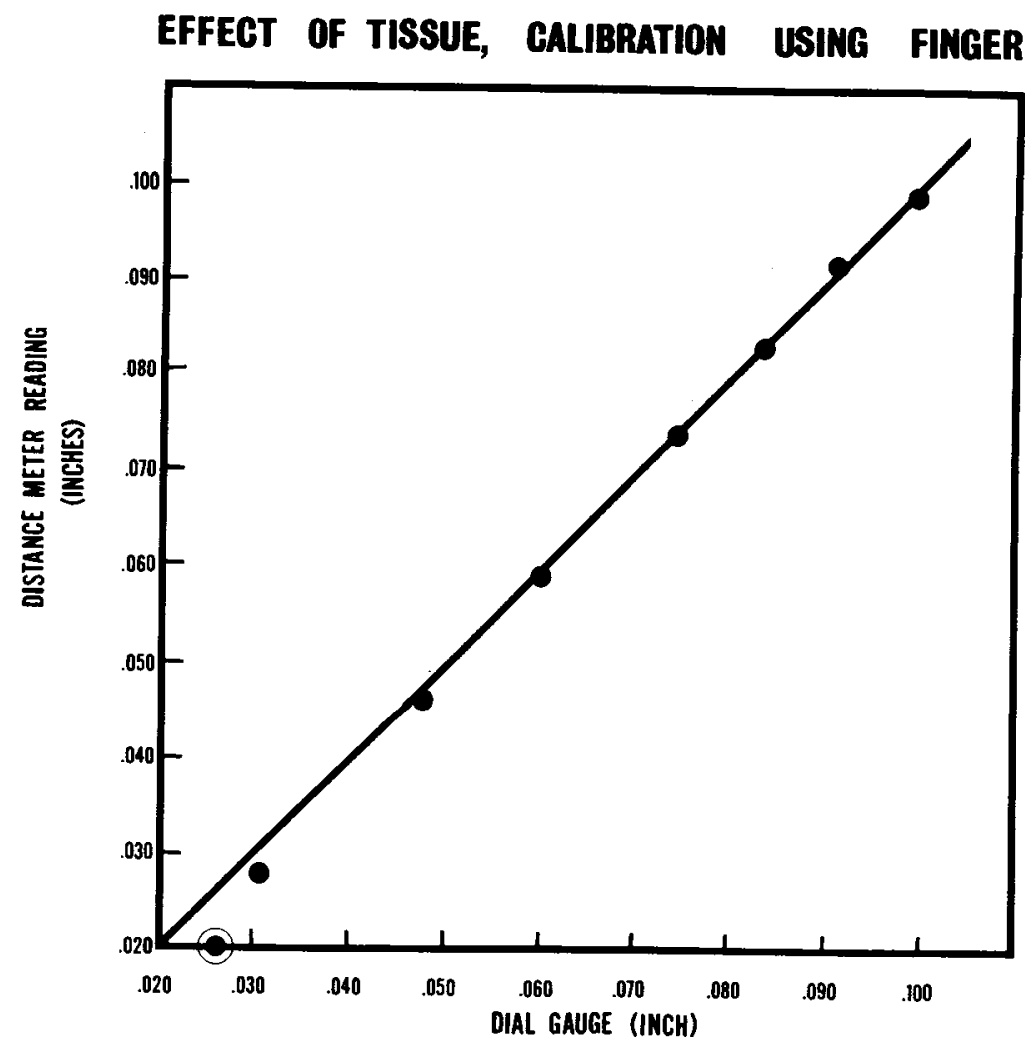

Frgure 2. Effect of tissue, calibration using finger. 


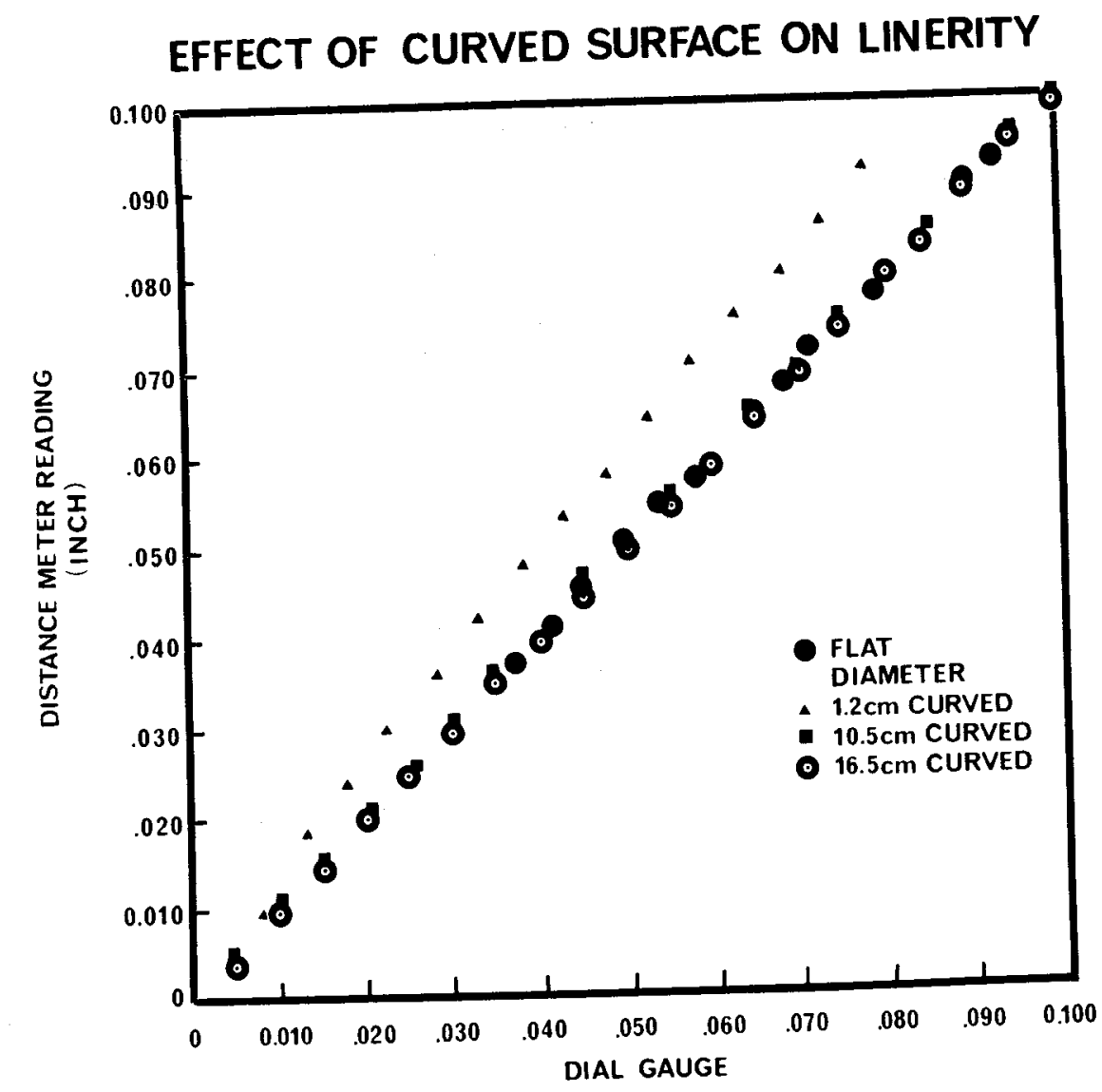

FigURE 3. Effect of curved surface on linearity.

PROBE DI-1140

VIBRATION METER B731A

2 OCT 64 CAL at DTMB

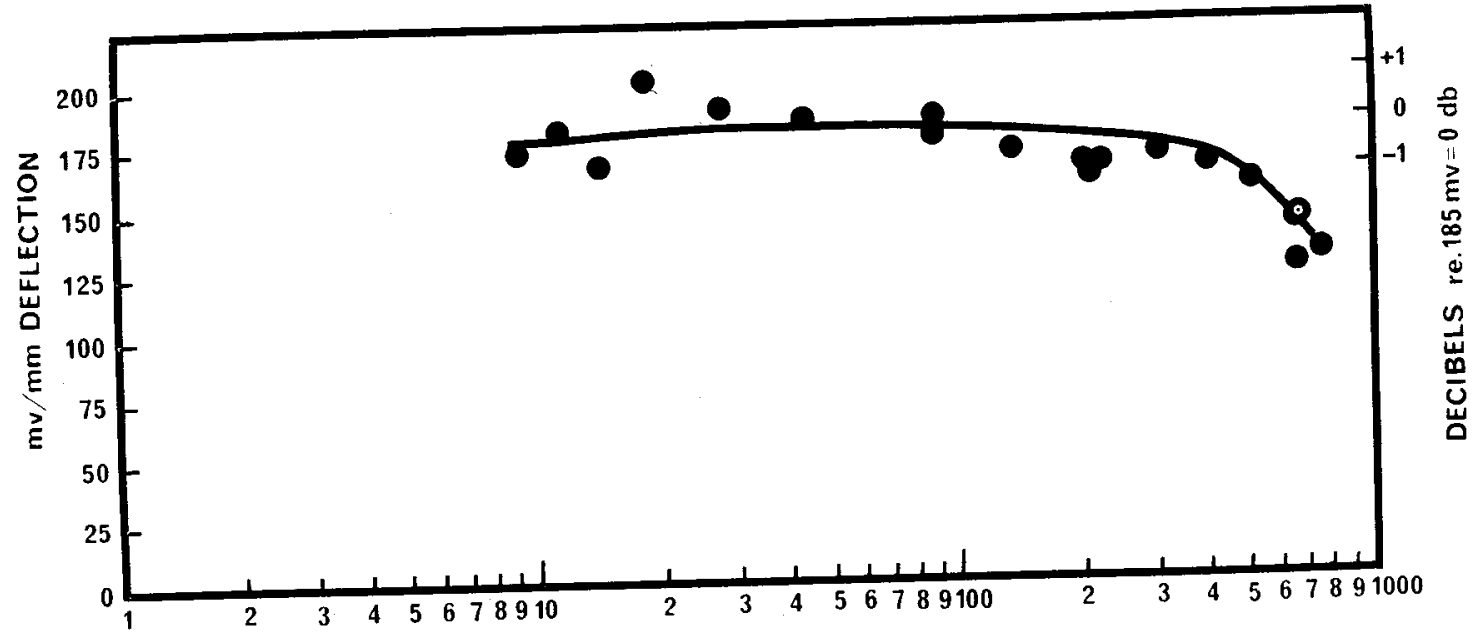

FIGURE 4. Frequency response characteristics. 


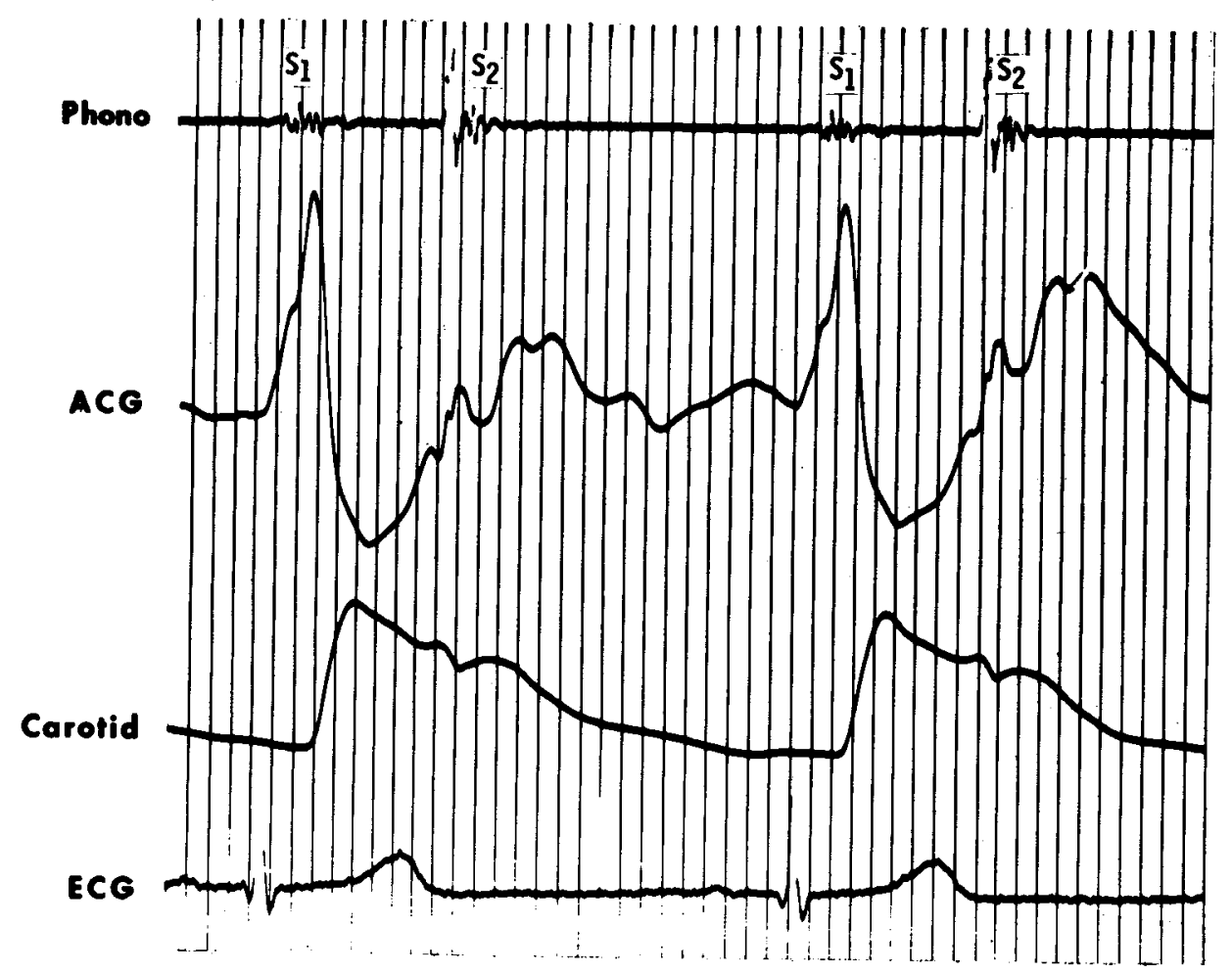

FIGURE 5. An apexcardiogram (ACG) taken with a conventional piezoelectric transducer. ECG, Carotid and Phono taken with conventional tranducers.

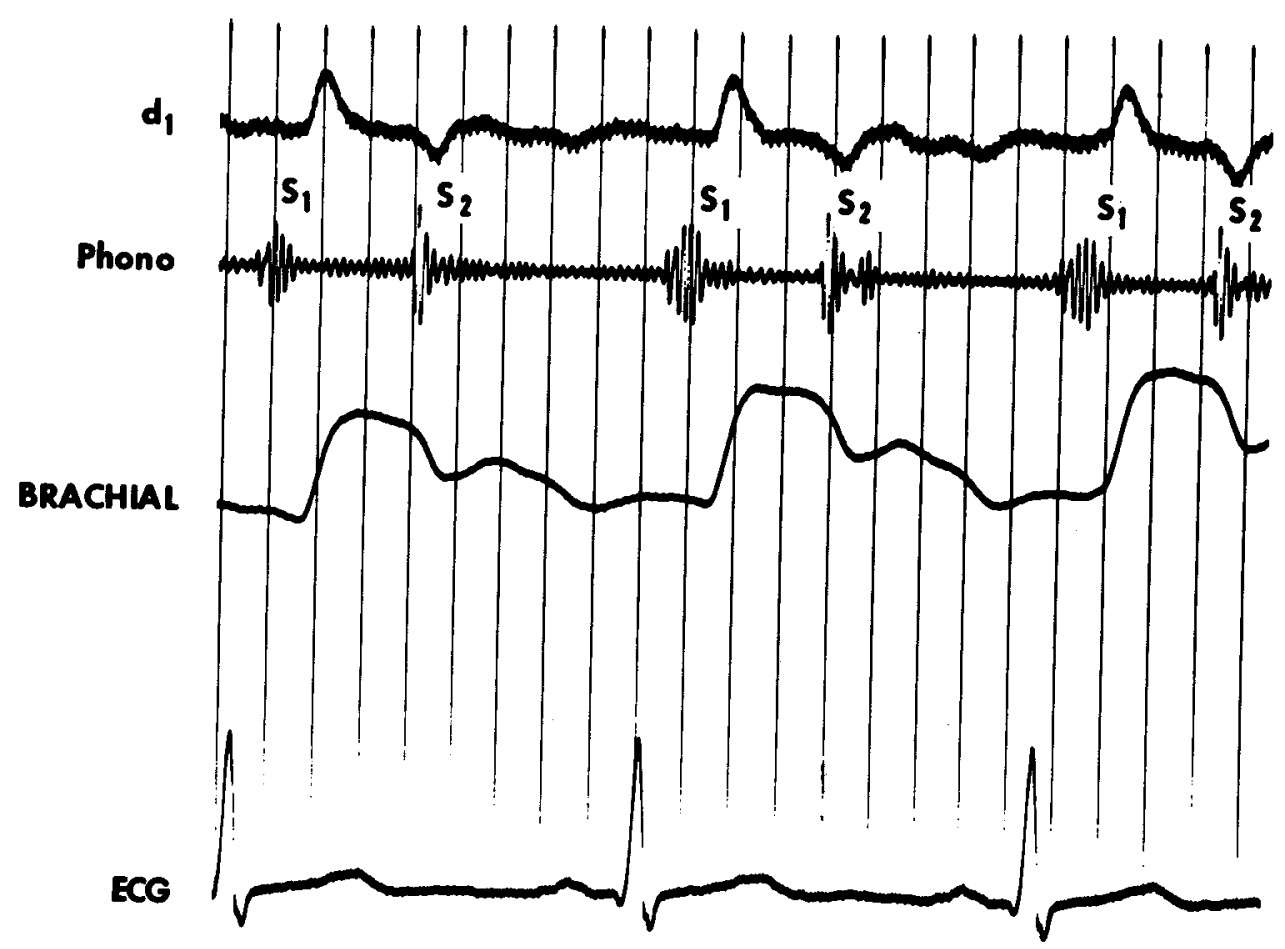

FIGURe 6. Brachial artery pulse and its derivative $d_{1}$. Phono taken by piezo-electric transducer. 


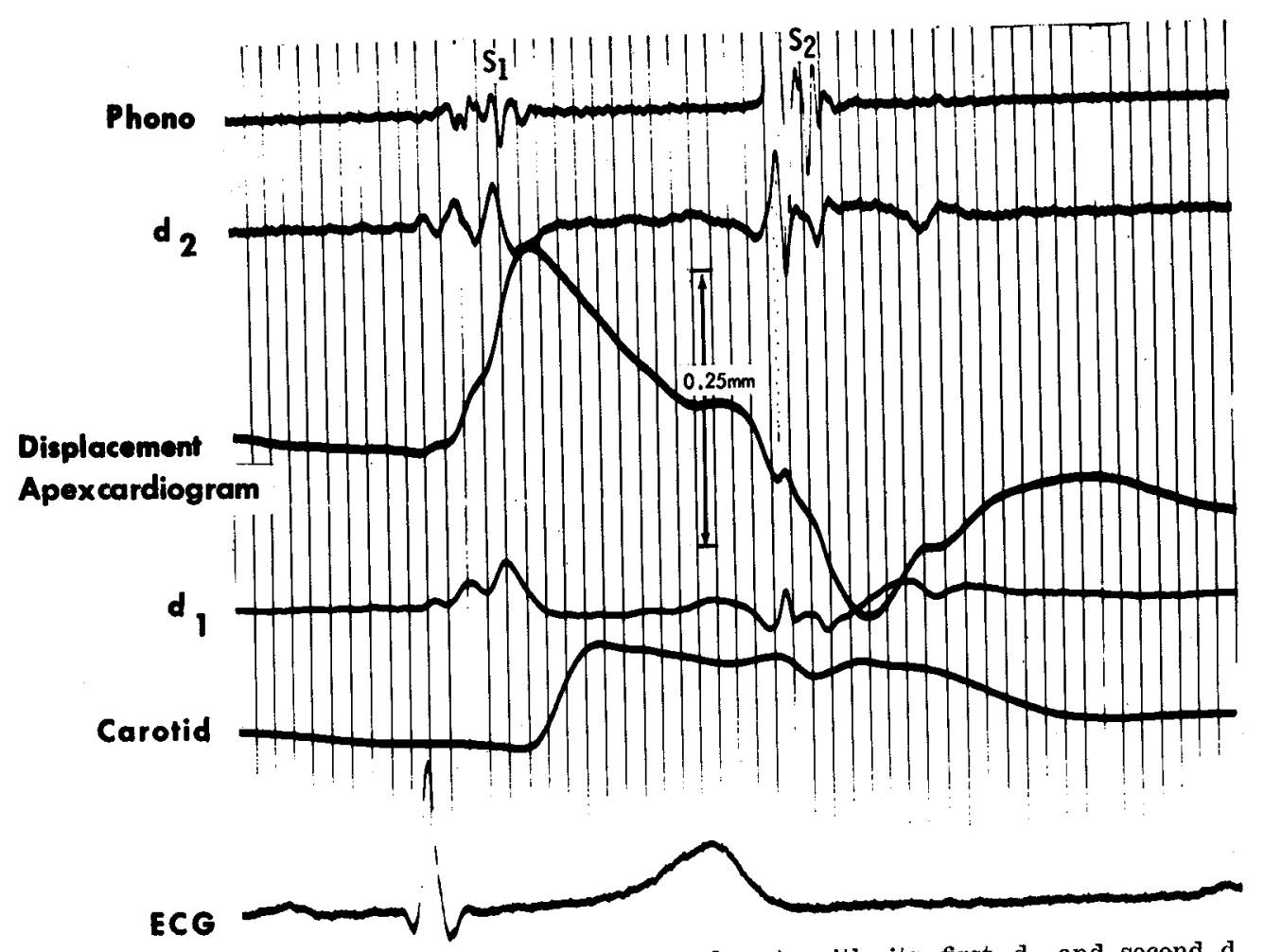

Fistre 7. A displacement apexcardiogram (capacitance transducer) with its first $d_{1}$ and second $d_{2}$ derivatives. The carotid pulse and phono taken with conventional transducers.

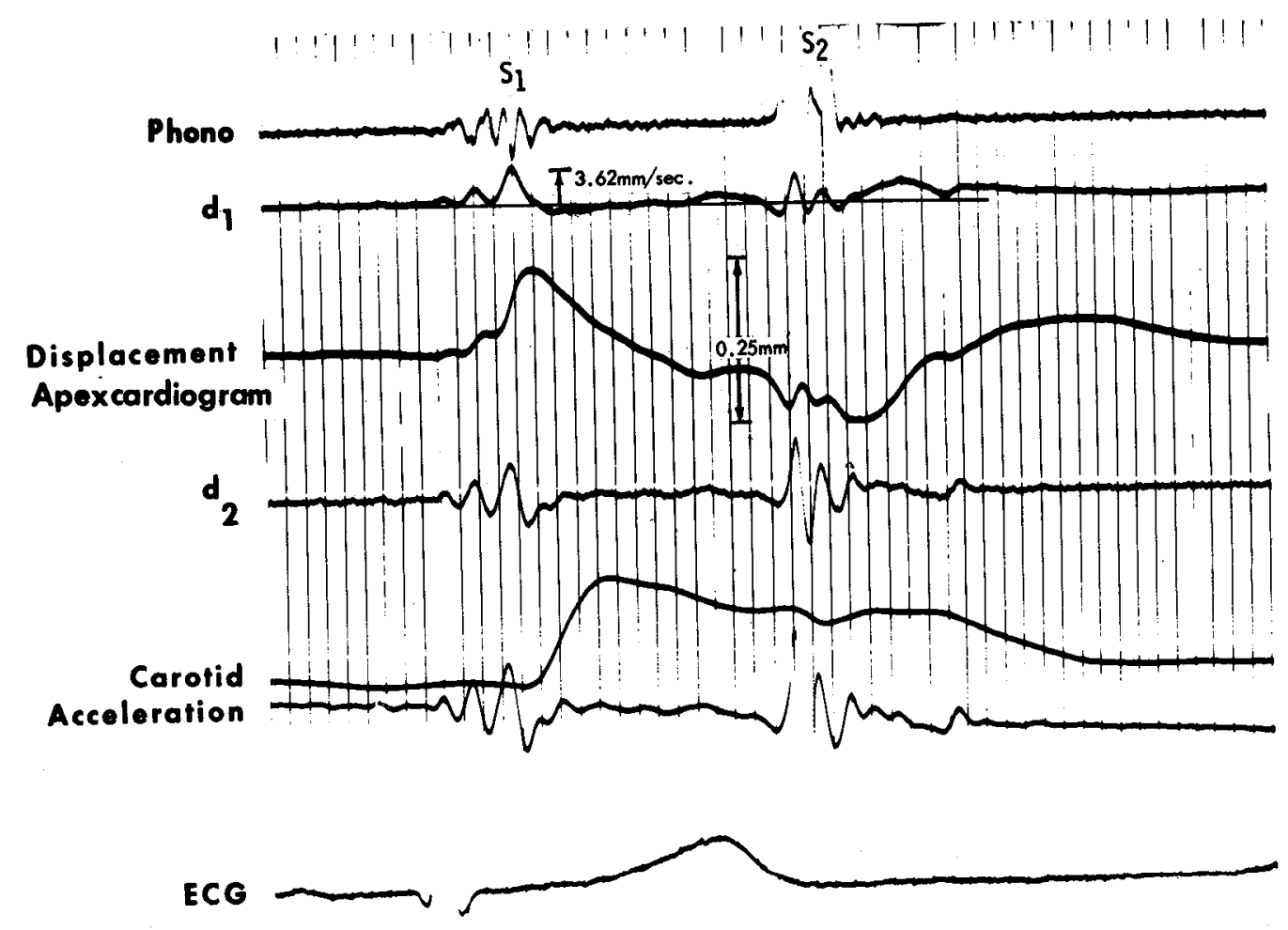

FIGURE 8. Comparison of the second derivative $d_{2}$ of the displacement apexcardiogram with the accelerometer output. 


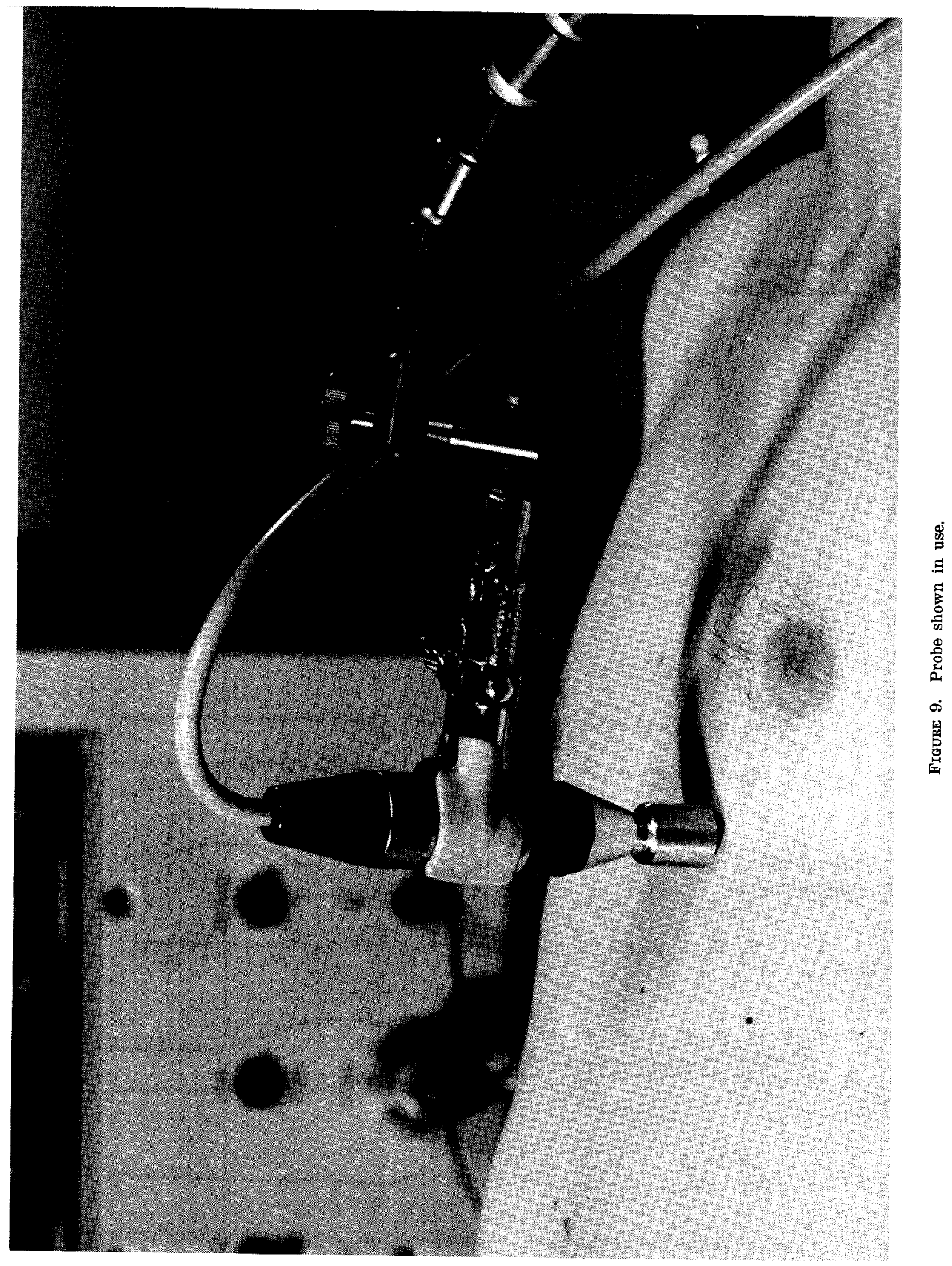

